\title{
Community Perception towards Traditional Healers and Health Centers on Management of Dog Bites and its Relation with Veterinary Public Health Activities
}

\author{
Kaba Tamirat ${ }^{*}$, Lemma Alemayehu ${ }^{2}$ and Tesfaye Mulualem ${ }^{3}$ \\ ${ }^{1}$ Ethiopian Institute of Agricultural Research, Holleta Agricultural Research Center, Ethiopia \\ ${ }^{2}$ Addis Ababa University, College of Veterinary Medicine and Agriculture, Head, Veterinary Teaching Hospital, \\ Debre Zeit, Ethiopia \\ ${ }^{3}$ Southern Region, Merab Abaya District Agricultural Office, Animal Health and Quarantine Department, Animal \\ Health Officer, Arba Minch, Ethiopia
}

${ }^{*}$ Corresponding author: Kaba T, DVM, Ethiopian Institute of Agricultural Research, Holleta Agricultural Research Center, Holleta, Ethiopia, P.O. Box: 2003, Fax: +251116460380, Tel: +251912298964, E-mail: tamirat11@gmail.com

Citation: Kaba Tamirat, Lemma Alemayehu, Tesfaye Mulualem (2016) Community Perception towards Traditional Healers and Health Centers on Management of Dog Bites and its Relation with Veterinary Public Health Activities. J Vet Sci Ani Husb 4(2): 204. doi: 10.15744/2348-9790.4.204

Received Date: October 29, 2015 Accepted Date: May 24, 2016 Published Date: May 26, 2016

\begin{abstract}
A survey was conducted to investigate whether the community uses traditional healers or modern health centers after exposure to dog bites and veterinary public health responses on the issues in Arba Minch, Ethiopia. Two stage cluster and simple random sampling procedures were employed to select inhabitants and other target study population for this study. The data were collected from 300 permanent inhabitants, 75 physicians, 28 veterinarians and 10 directors and vice directors of health centers/hospital through personal interview face to face using pre-tested structured questionnaires. Among the permanent inhabitants, 36.9\% faced one or more incidents of dog bite in their family in past twelve months. Out of those victims the majority (42.45\%) used treatment by traditional healers. The majority (60.6\%) of the respondents (both victim and non victim families) accepted the practice of traditional healers. Statistically significant difference $(\mathrm{P}<0.05)$ was observed between; residents living area, economic statues, educational level and the choice of treatment (traditional healers, health centers or both) for dog bite. Statistically significant difference $(\mathrm{P}<0.05)$ was also observed between; purpose of keeping dog, vaccination practice, reason not to vaccinate, economic status and residents' living area. Analysis of data from directors/vice directors of health centers revealed higher proportion (70\%) of directors/vice directors believe that veterinarians should be very much involved in zoonoses education for the patients. It was also confirmed by large proportion (60\%) of officials that there was no health center/institution/hospital with a department specifically working on zoonoses in the area. Smaller proportions (40\%) of directors/vice directors of health centers/hospital responded there were zoonoses departments in health centers, but without public health veterinarians. In the conclusion, this study confirmed the high preference common use of traditional healers to modern health centers for rabies suspected dog bite management. Besides, the study revealed a very minimal role of veterinary public health in the area. Strong participatory education about the risk of dog bites and rabies should be given to the residents of the area.
\end{abstract}

Keywords: Dog bite; Community perception; Rabies; Traditional healers; Health centers

List of abbreviations: USA: United State of America; PEP: Post Exposure Prophylaxis; CDC: Center for Disease Control and Prevention; WHO: World Health Organization; OPHS: Ontario Public Health Standard; CSAE: Central Statistic Agency Ethiopia

\section{Introduction}

Domestic dogs serve people in many important ways; guarding property and domestic livestock, assisting the blind and other disabled people, performing search and rescue missions, acting as sled animals, detecting explosives and drugs etc [1]. Attitudes regarding dogs greatly vary according to socio-cultural and religious background. Dogs are used ubiquitously for guarding and this role is appreciated even by those people whose religious belief deems them as impure [2]. In Ethiopia many households own dogs usually for guarding and entertaining in urban; herding and hunting in rural community [3]. But, no formal data available about the dog population at national level, usually estimated one owned dog per five household [4] and dogs are poorly managed especially in rural community and vaccination of dogs against rabies is limited to only capital city of nation and few regional towns. 
Despite all the activities that dogs contribute to humans, they are unwittingly reservoir, carrier and transmitters of many zoonotic diseases. The methods of transmission of infection from dog to human include: direct contact, indirectly through environmental contamination or by vectors [5]. The major issue and social conflict of human-dog contact in cities is Dog bites. It is a serious threat to public health both in urban and rural area of the country in recent years and the most important public health concern because of the associated physical and psychological trauma, wound infections by different microorganisms and the risk of rabies transmission [6], death from injury and tremendous cost of treatment [7]. Rabies is only one of the many diseases transmitted from dogs to human through dog bite and is a serious, almost always fatal disease that should be considered as a potential consequence of any dog bite [5,8]. According to the study by Charles [9], about 90\% of human rabies case was due to dog bite. Besides rabies infection, fatal injury is another consequence of dog bite especially in children [10]. Overall KL, Love M [11] stated, in the United State of America (U.S.A), dog bites cause an estimated number 333,687 injuries resulting in the need for medical attention every 3 years. Over 5-years period, 74 deaths attributable to dog bites were reported in U.S.A. (death associated with only dog's attacks and not associated with infection secondary to dog bites) and most of them (75\%) were children < 10 years old. In Ethiopia However, dog bites are under-reported in health facilities resulting in missed cases and misclassification of deaths due to rabies [12]. In Addis Ababa during study period between 2008-2009 Mengistu et al. [13] reported the proportion of different animals' bites in human. Among them, the proportion of stray dog bites was highest (53.8\%) followed by owned dog bite (40.5\%). There was no official information on the dog bite statues in this study region of the country indeed, but health centers record book of the area revealed, an average of $46 \mathrm{dog}$ bite cases per a year (recent documents of health centers).

The important components in the management of dog bite in human are immediate wound treatment and proper post exposure prophylactic (PEP) administration [14]. Studies of rabies and other infections transmission in experimentally exposed animals have demonstrated that thoroughly wound cleaning alone markedly reduces the likelihood of the infection [15]. Post exposure management should follow the national guidelines which are usually based on World Health Organization (WHO) [16] recommendations. According to the recommendations, management of dog that bite human is the next step after thoroughly washing of the wound if the dog is available for close observation. Regardless of vaccination status, a healthy dog that has bitten human should be confined and observed daily for at least 10 days from the time of the exposure by veterinarian [17,18]. The remark of this recommendation by WHO is because of dog bites are used as a proxy for suspect rabies cases in humans for rabies surveillance and response system. Administration of rabies vaccine to the animal is not recommended during the observation period to prevent confusion between signs of rabies and rare adverse reaction $[14,19]$. Any illness in the animal should be reported immediately to the local health department. Animals should be evaluated at the first sign of illness during confinement. If signs suggestive of rabies develop, PEP should be initiated and the dog should be euthanized and the head submitted for testing. If the dog's laboratory results are negative, PEP should be discontinued. WHO [20] strongly emphasizes that communication and collaboration between the medical and veterinarians in their working practices can lead to control and prevention bite related risks. Delaying the initiation of PEP while observing animal for 10 days in the quarantine is recommended if the following conditions are met; if the animal is a domestic pet, fully vaccinated, the bite was provoked and there is very low prevalence of rabies in the area [21]. Many reports regarding on post exposure intervention have emphasized the intervention requires the collaborative efforts between public health institution, department of agriculture, diagnostic centers, physicians and veterinarians [17,22].

The associated risks of dog bite in most developing countries are not only due to the frequency of exposure (bite), but also to the failure of taking appropriate measure after exposure [23]. Appropriate treatment may not be available or is underestimated by traditional or religious beliefs, assuming that their traditional belief is superior to appropriate routine post exposure management $[8,24]$. In Ethiopia, few studies have been conducted to assess community awareness towards rabies infection [8,24-26] but, those studies were confined to the capital city of Ethiopia (Addis Ababa), and lack the information on community perception about management of dog bite. Therefore, the objectives of this study were to assess the community views on the management of human dog bite and to evaluate collaborative effort between veterinarians and physicians in the area.

\section{Materials and Methods}

\section{Study Area and Target Population}

This study was conducted in Arba Minch, Ethiopia and its surrounding districts (Zuria districts) from December, 2014 up to October, 2015. Arba Minch is a town and separate district in southern Ethiopia. It is located about 500 kilometers south of Addis Ababa, at an elevation of 1285 meters above sea level. It is the second largest town in Southern region next to Awassa and surrounded by others small administrative districts (Zuria districts). Based on the 2007 Census conducted by the Central Statistical Agency of Ethiopia (CSAE) the town has a total population of 239408, of whom 121407 are men and 118001 women including surrounding Zuria districts. The rural villages of Arba Minch Zuria district are found at an altitude ranging from $1187 \mathrm{Kms}$ to a peak of 2700 meters above sea level with an average annual temperature of $23.6{ }^{\circ} \mathrm{C}$ and a rainfall of $950 \mathrm{~mm}$. Arba Minch town is administratively divided in to four kifle-ketemas (sub-towns) which are further subdivided into sixteen kebeles (lowest administrative structure). Arba Minch Zuria District consists of 30 kebeles and which means a total of 46 kebeles (kebeles of Arba Minch town and Zuria districts). The majority of the inhabitants practiced Ethiopian Orthodox Christianity, with 56.04\% of the population reporting that belief, 38.47\% were Protestants, and $4.16 \%$ were Muslim [27]. The target population comprised of permanent inhabitants of the town and Zuria districts, physicians, veterinarians and directors and vice directors of health centers including hospitals. 


\section{Study Design}

The survey was conducted to assess the precautionary measures taken by the community after exposure to dog bite and the activities of veterinary public health issue in Arba Minch and its Zuria districts. Semi structured questionnaires supplemented with interview were administered to 413 people through face to face, of whom 300 permanent inhabitants, 75 physicians, 28 veterinarians and 10 directors and vice directors of four health centers and one hospital. For permanent inhabitants, questionnaire was designed to collect information about the respondents' knowledge of the dog bite consequences, attitudes and practice about management and prevention of dog bite complication, perception of community for veterinarians' role as well as house hold information. Regarding physicians, veterinarians and directors and vice directors of the area, questionnaire focused on the assessment of collaborative activity of the two professionals dealing with zoonoses and structure of veterinary public health activity if available.

\section{Sampling Methods and Sample Size}

Permanent inhabitants of the town and Zuria districts were selected by two stage cluster sampling method, (kebeles of the town and Zuria districts were sampled by a simple random method in a cluster as primary sampling unit and then, inhabitants within those kebeles were selected by simple random technique as secondary sampling unit). The formulae in two stage cluster sampling method was used according to the method described by Levy and Lemeshow [28] to determine the sample size of permanent inhabitants; according to the method, kebeles were grouped in to urban and rural and equal ratio of cluster was provided for urban to rural sample size which means a total of 30 kebeles (10 from urban and 20 from rural) were selected, the assumptions used were $95 \%$ confidence interval, $50 \%$ expected frequency and 0.0157 between cluster-variance (i.e. a potential large variation that could occur between clusters "kebeles"). The target population was household heads or their spouses who had lived in the area as permanent residents for more than six months. A simple random sampling technique was used to sample physicians from the list of their respective health centers and hospital. Due to the low number of veterinarians in the area, we were supposed to include all veterinarians working in government institution, non-governmental (NGO) organization and private sectors in the survey.

A sample size formula for two stage cluster sampling for permanent inhabitants in Arba Minch, Ethiopia was as follows:

$\mathrm{T}_{\mathrm{s}}=1.96^{2} \mathrm{Gg} \mathrm{P}_{\exp }\left(1-\mathrm{P}_{\exp }\right)$

$\mathrm{Ggd}^{2}-1.96^{2} \mathrm{~V}_{\mathrm{c}}(\mathrm{G}-\mathrm{g})$

Where; $T_{s}$, total number of permanent residents to be sampled

$\mathrm{g}$, the number of clusters to be sampled

$\mathrm{d}$, desired absolute precision (5\%)

$\mathrm{P}_{\text {exp }}$, expected frequency $(50 \%)$

$\mathrm{V}_{c}$, between cluster variance $(0.0157)$

$\mathrm{G}$, total number of clusters in the population (46 kebeles)

$\mathrm{V}_{\mathrm{c}}=\mathrm{c}\{\mathrm{k} 1 \mathrm{cv}-\mathrm{k} 2 \mathrm{p}(1-\mathrm{p})\}$

$\mathrm{T}^{2}(\mathrm{c}-1) \mathrm{T}$

Where, c; number of cluster (kebeles) in the sample

$\mathrm{T}$; total number of residents to be sampled

$\mathrm{K} 1=(\mathrm{C}-\mathrm{c}) / \mathrm{C}$ Where, $\mathrm{C}$; number of clusters (kebeles) in the population

$\mathrm{K} 2=(\mathrm{N}-\mathrm{T}) / \mathrm{N}$ Where, $\mathrm{N}$; total number of households in the population

$\mathrm{V}=\mathrm{p}^{2}\left(\sum \mathrm{n}^{2}\right)-2 \mathrm{p}\left(\sum \mathrm{nm}\right)+\left(\sum \mathrm{m}^{2}\right)$

Where, p; sample estimate of overall prevalence (50\%)

$\mathrm{n}$; number of inhabitants in each cluster (kebele)

$\mathrm{m}$; number of inhabitants sampled in each cluster (kebele)

\section{Data Management and Analysis}

All data generated during study were entered into MS-excel program and statistical analysis was performed by SPSS statistical software version 20 Chicago, IL 60606, USA. Descriptive statistics and Pearson's chi square were used to analyze quantitative data and the association between variables respectively. Statistical significance was considered at $\mathrm{p}<0.05$.

\section{Results}

\section{Socio-Demographic Features}

A total of 300 permanent inhabitants were interviewed during the study period. Of these, data collected from 13 respondents was incomplete, and excluded from analyses. Data obtained from 28 respondents was analyzed and accordingly, the age of respondents was ranged 18-70 years, the majority of the respondents age (38\%) was between $39-45$ years and most were male respondents (75.3\%). Among the participant, $42.2 \%$ had diploma and above educational status, $36.2 \%$ were high school complete and $21.6 \%$ were 
high school complete and $21.6 \%$ were illiterate. Concerning religion, the majorities (40.1\%) were Orthodox Christian, $32.1 \%$ were Protestant, 19.5\% were Muslim and the rest in other religion. Among 287 respondents, (36.9\%) of family members had a history of dog bite and (34.5\%) of the respondents had dog at their home. The majority of respondents (37.6\%) had lowest monthly income and higher proportion of them live in rural area (Table 1).

\begin{tabular}{|c|c|}
\hline Variables/factors & Number (\%) \\
\hline \multicolumn{2}{|l|}{ Age } \\
\hline $18-25 Y$ & $67(23.3)$ \\
\hline $26-35 Y$ & $80(27.9)$ \\
\hline $36-45 \mathrm{Y}$ & $109(38)$ \\
\hline above $45 \mathrm{Y}$ & $31(10.8)$ \\
\hline \multicolumn{2}{|l|}{ Sex } \\
\hline $\mathrm{m}$ & $216(75.3)$ \\
\hline$f$ & $71(24.7)$ \\
\hline \multicolumn{2}{|l|}{ Religion } \\
\hline Christian Orthodox & $112(39)$ \\
\hline Muslim & $53(18.5)$ \\
\hline protestant & $99(32.1)$ \\
\hline other & $23(8)$ \\
\hline \multicolumn{2}{|l|}{ Residents' area } \\
\hline urban & $110(38.3)$ \\
\hline rural & $177(61.7)$ \\
\hline \multicolumn{2}{|l|}{ Education status } \\
\hline diploma and above & $121(42.2)$ \\
\hline high school complete & $104(36.2)$ \\
\hline illiterate & $62(21.6)$ \\
\hline \multicolumn{2}{|l|}{ Economic rank } \\
\hline Higher income (>101 USD/month) & $79(27.5)$ \\
\hline Lower income 50-100 USD/M & $84(29.3)$ \\
\hline Lowest (<50 USD) & $124(43.2)$ \\
\hline \multicolumn{2}{|l|}{ Owning dog } \\
\hline yes & $99(34.5)$ \\
\hline no & $188(65.5)$ \\
\hline \multicolumn{2}{|l|}{ Exposed to dog bite } \\
\hline yes & $106(36.9)$ \\
\hline no & $181(63.1)$ \\
\hline
\end{tabular}

Table 1: Frequencies and percentages of socio demographic features and other factors of the study population (permanent inhabitants) in Arba Minch, Ethiopia 2015

\section{Community's practices on dog bite management}

From 287 participants, 106 (36.9\%) one or more family members had dog bite exposure so far, out of those victims family, the majority $(42.45 \%)$ used treatment by traditional healers, $33.02 \%$ sought medical services and $24.53 \%$ used both traditional and health center services as indicated in Figure 1. Respondents with the history of dog bite and without a dog bite history were asked on their preference of taking a dog bite victim or patient to traditional healer versus modern health centers. The study revealed a high proportion of respondents $60.6 \%$ (95\% CI, 48.9-71.0\%) moderately preferred traditional healers (with mean 2.25 in the range response scale $(1-4$, S.D. $=0.99)($ Table 2$)$.

\begin{tabular}{|c|c|c|}
\hline Level of preferences (4) & Number (\%) & $\mathbf{9 5 \% ~ C I ~}$ \\
\hline High preference (<2) & $78(27.2)$ & $22-32.8$ \\
\hline Moderate preference (2-3) & $174(60.6)$ & $48.9-71$ \\
\hline Low preference $>3$ & $35(12.2)$ & $8.4-16$ \\
\hline
\end{tabular}

Table 2: The degree of preference of inhabitants on traditional healers in Arba Minch Ethiopia, (2015) 


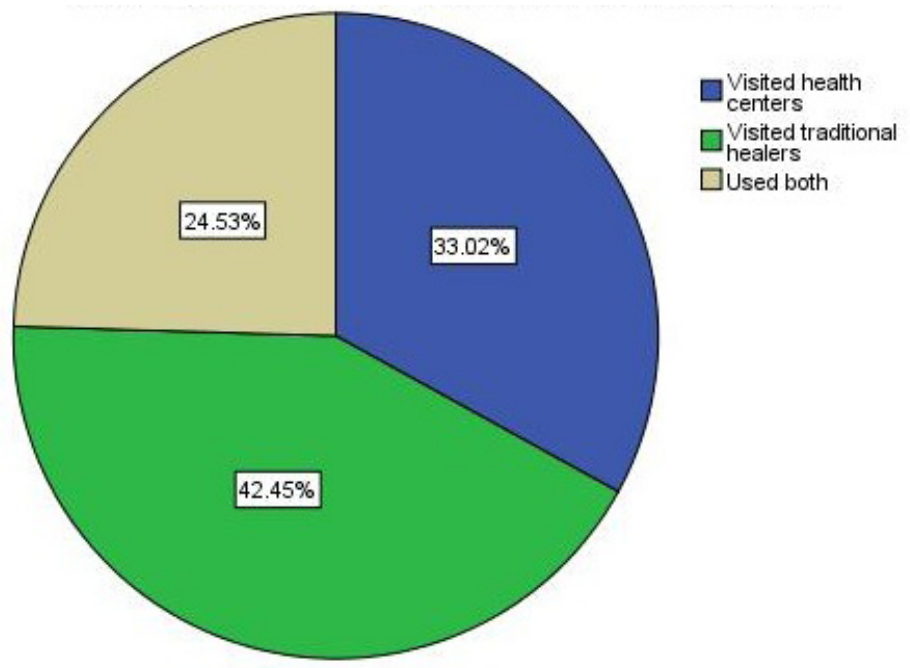

Figure 1: The proportion of respondents who visited traditional healers, health centers and used both services after exposure to dog bite in Arab Minch Ethiopia

\section{Factors Associated With the Choices of Treatment Methods}

Association between independent variables and the methods of dog bite treatment was calculated using Pearson's Chi square (Table 3). Respondents' living area was significantly associated with the choices of treatment methods $\left(\mathrm{X}^{2}=9.2, \mathrm{P}<0.05\right)$. Thirty four $(47.2 \%)$ of rural residents used traditional treatment and eighteen (52.9\%) of urban residents sought medical services. Twenty one (29.2\%) of respondents in rural and five (14.7\%) in urban used both traditional and medical services. Most of the respondents who used both traditional and health centers services had witnessed, they applied traditional medicine before they visited health centers. The association between education status and the choices of treatment practices after exposure was statistically significant $\left(\mathrm{X}^{2}=27.5, \mathrm{p}<0.05\right.$. The majority of respondents $(61.8 \%)$ that visited health centers had at least diploma or above educational level. And conversely higher numbers (42.3\%) of respondents that visited traditional healers were relatively less educated. Statistically significant difference was also observed between the economic status and the choices of treatment methods $\left(\mathrm{X}^{2}=35.2, \mathrm{P}<0.05\right)$. The highest proportion (64.5\%) of respondents with higher income sought modern medical services, whereas most (64.2\%) of the lowest income respondents used traditional method. This study found that no statistical association exists between choices of treatment methods and: age $\left(\mathrm{X}^{2}=7.793, \mathrm{P}>0.05\right)$, sex $\left(\mathrm{X}^{2}=4.043, \mathrm{P}>0.05\right)$, religion $\left(\mathrm{X}^{2}=12.4, \mathrm{P}>0.05\right)$, ease access to health centers $\left(X^{2}=1, P>0.05\right)$, severity of wound $\left(X^{2}=2, p>0.05\right)$ and knowledge of the risk $\left(X^{2}=2, P>0.05\right)$. Participants' knowledge about dog bite risks was evaluated by the response to open ended question on what they think the associated risks of getting bitten by the dog. Higher respondents (79.4\%) have indicated rabies is the only consequence associated with dog bite. Only $20.6 \%$ of respondents have shown other infections at site of bite, bleeding and Psychological trauma are also risks associated with bite besides rabies.

\begin{tabular}{|c|c|c|c|c|c|c|}
\hline & \multicolumn{3}{|c|}{ Methods of treatment } & $\mathbf{X}^{2}$ & Df & P \\
\hline & Health center & Traditional & Both & & & \\
\hline Variables/Factors & Number (\%) & Number (\%) & Number (\%) & & & \\
\hline Age & & & & 7.793 & 6 & 0.254 \\
\hline $18-25 Y$ & $13(46.6)$ & $11(39.3)$ & $4(14.3)$ & & & \\
\hline $26-35 Y$ & $9(33.3)$ & $8(29.6)$ & $10(37)$ & & & \\
\hline $36-45 Y$ & $12(27.3)$ & $22(50)$ & $10(22.7)$ & & & \\
\hline above 45Y & $1(14.3)$ & $4(57.1)$ & $2(28.6)$ & & & \\
\hline Sex & & & & 4.043 & 2 & 0.132 \\
\hline male & $25(32.9)$ & $36(47.4)$ & $15(19.7)$ & & & \\
\hline female & $10(33.3)$ & $9(30)$ & $11(36.7)$ & & & \\
\hline Religion & & & & 12.49 & 6 & 0.052 \\
\hline Christian Orthodox & $7(22.6)$ & $18(58.1)$ & $6(19.4)$ & & & \\
\hline Muslim & $13(56.5)$ & $3(13)$ & $7(30.4)$ & & & \\
\hline protestant & $11(28.2)$ & $18(46.2)$ & $10(25.6)$ & & & \\
\hline others & $4(30.8)$ & $6(46.2)$ & $3(23.1)$ & & & \\
\hline Living area & & & & 9.2 & 2 & 0.010 \\
\hline urban & $18(52.9)$ & $11(32.4)$ & $5(14.7)$ & & & \\
\hline rural & $17(23.6)$ & $34(47.2)$ & $21(29.2)$ & & & \\
\hline
\end{tabular}




\begin{tabular}{|c|c|c|c|c|c|c|}
\hline & \multicolumn{3}{|c|}{ Methods of treatment } & \multirow[t]{2}{*}{$\mathrm{X}^{2}$} & \multirow[t]{2}{*}{ Df } & \multirow[t]{2}{*}{$\mathbf{P}$} \\
\hline & Health center & Traditional & Both & & & \\
\hline Education status & & & & 27.5 & 4 & 0.000 \\
\hline diploma and above & $21(61.8)$ & $4(11.8)$ & $9(26.5)$ & & & \\
\hline high school complete & $6(13)$ & $30(65.2)$ & $10(21.7)$ & & & \\
\hline illiterate & $8(30.8)$ & $11(42.3)$ & $7(26.9)$ & & & \\
\hline Economic rank & & & & 35.2 & 4 & 0.000 \\
\hline Higher income (>101 USD/month) & $20(64.5)$ & $4(12.9)$ & $7(22.6)$ & & & \\
\hline Lower income 50-100 USD/M & $11(50)$ & $7(31.8)$ & $4(18.2)$ & & & \\
\hline Lowest (<50 USD) & $4(7.5)$ & $34(64.2)$ & $15(28.3)$ & & & \\
\hline Ease access to health center & & & & 1 & 2 & 0.640 \\
\hline yes & $26(35.6)$ & $29(39.7)$ & $18(24.8)$ & & & \\
\hline no & $9(27.3)$ & $16(48.5)$ & $8(24.2)$ & & & \\
\hline Severity of wound dictates & & & & 2 & 2 & 0.371 \\
\hline yes & $4(57.1)$ & $2(28.6)$ & $1(14.3)$ & & & \\
\hline no & $31(31.3)$ & $43(43.4)$ & $25(25.3)$ & & & \\
\hline Knowledge of the risks & & & & 2 & 2 & 0.364 \\
\hline yes & $26(30.2)$ & $37(43)$ & $23(26.7)$ & & & \\
\hline no & $9(45)$ & $8(40)$ & $3(15)$ & & & \\
\hline
\end{tabular}

Table 3: The relation between choices of treatment methods and some independent variables among the respondents in Arba Minch, Ethiopia, 2015

\section{Dog Management Practices}

Dog keeping practice of the study area was not significantly different between urban and rural community $\left(\mathrm{X}^{2}=3.327, \mathrm{P}>0.05\right)$. The majority of the respondents (32.9\%) in urban and (67.1\%) in rural let their dogs free. The purpose of keeping dog was significantly associated with the residents' living area $\left(\mathrm{X}^{2}=26.431, \mathrm{P}<0.05\right)$. Urban respondents indicated they keep dogs for guarding $(51.5 \%)$ and entertaining (100\%) purpose whereas, rural respondents for herding (100\%), hunting (100\%) and guarding (48.5\%). Vaccination practice was also significantly different between urban and rural residents $\left(\mathrm{X}^{2}=11.679, \mathrm{P}<0.05\right)$. Six $(100 \%)$ urban residents responded they have vaccinated their dogs, while none $(0 \%)$ of the rural residents witnessed they have vaccinated their dogs. The reason that the respondents have not vaccinated their dog was also associated with urban and rural residents $\left(\mathrm{X}^{2}\right.$ $=19.950, \mathrm{P}<0.05)$. Eleven $(73.3 \%)$ of urban respondents responded it was due to lack of attention and lack of knowledge $(22.9 \%)$. Lack of veterinary services $(90.9 \%)$ and lack of knowledge $(77.1 \%)$ were the main reason in rural residents. Residents' living area and economic status were significantly different $\left(\mathrm{X}^{2}=74.2, \mathrm{P}<0.05\right) .47 .3 \%$ of urban residents had higher income and $62.7 \%$ of rural residents had lowest income (Table 4).

\begin{tabular}{|c|c|c|c|c|c|}
\hline & \multicolumn{2}{|c|}{ Residents' living area } & $\mathbf{X}^{2}$ & Df & P \\
\hline & Urban & Rural & & & \\
\hline Variables/factors & $\mathbf{N}(\%)$ & $\mathbf{N}(\%)$ & & & \\
\hline Dog keeping practice & & & 3.327 & 1 & 0.068 \\
\hline Let free & $26(32.9)$ & $53(67.1)$ & & & \\
\hline Tie (keep indoor) & $11(55)$ & $9(45)$ & & & \\
\hline Purpose of keeping & & & 26.431 & 3 & 0.000 \\
\hline guarding & $35(51.5)$ & $33(48.5)$ & & & \\
\hline hunting & $0(0)$ & $9(100)$ & & & \\
\hline entertaining & $2(100)$ & $0(0)$ & & & \\
\hline herding & $0(0)$ & $20(100)$ & & & \\
\hline Vaccination practice & & & 11.679 & 1 & 0.001 \\
\hline yes & $6(100)$ & $0(0)$ & & & \\
\hline no & $29(31.2)$ & $64(68.8)$ & & & \\
\hline Lack of knowledge & $11(22.9)$ & $37(77.1)$ & & & \\
\hline expensive & $1(50)$ & $1(50)$ & & & \\
\hline Reason not to vaccinate & $2(9.1)$ & $20(90.9)$ & & & \\
\hline No vet clinic nearby & $11(73.3)$ & $4(26.7)$ & & & \\
\hline Lack oftention & & & & \\
\hline
\end{tabular}




\begin{tabular}{|c|c|c|c|c|c|}
\hline & \multicolumn{2}{|c|}{ Residents' living area } & $\mathbf{X}^{2}$ & Df & P \\
\hline & Urban & Rural & & & \\
\hline Economic rank & & & 74.2 & 2 & 0.000 \\
\hline Higher income (>101 USD/month) & $52(47.3)$ & $27(15.3)$ & & & \\
\hline Lower income 50-100 USD/M & $45(40.9)$ & $39(22)$ & & & \\
\hline Lowest (<50 USD) & $13(11.8)$ & $111(62.7)$ & & & \\
\hline
\end{tabular}

Table 4: The relation between residents living area and some independent factors among inhabitants of Arba Minch, Ethiopia, 2015

\section{Owning the $\operatorname{dog} \mathrm{V}_{\mathrm{s}}$ Exposure to Bite}

Owning a dog was not significantly associated with dog bite exposure in the study area $\left(\mathrm{X}^{2}=0.162, \mathrm{P}>0.05\right)$ (Table 5$)$.

\begin{tabular}{|c|c|c|c|c|c|c|}
\hline & \multicolumn{2}{|c|}{ Exposure to bite } & $\mathbf{X}^{2}$ & Df & P & Total \\
\hline & Yes & No & & & & \\
\hline Factor & $\mathbf{N}(\%)$ & $\mathbf{N}(\%)$ & & & & \\
\hline Owning dog & & & 0.162 & 1 & 0.687 & \\
\hline yes & $35(33)$ & $64(35.4)$ & & & & $99(34.5)$ \\
\hline no & $71(67)$ & $117(64.6)$ & & & & $188(65.5)$ \\
\hline Total & $106(100)$ & $181(100)$ & & & & \\
\hline
\end{tabular}

Table 5: The relation between owning the dog and exposure to dog bite among the inhabitants of Arba Minch, Ethiopia 2015

\section{Veterinary public health responses}

In open ended question, residents were asked what they know about the role of veterinarians working around; higher respondents (59.9\%) responded veterinarians deal with only animal health while only $40.1 \%$ of respondents indicated veterinarians educate people about animal related risk, inspect food of animal origin in addition to dealing with animal health. Moreover, participants were also asked about their perception towards the capabilities of veterinarians in educating people about animals associated risks. Accordingly, lower proportion of respondents (43.6\%) believes that veterinarians are capable of educating about animals related risks (Figure 2). Statistically significant difference was observed between education statuses; knowledge of veterinarians' role $\left(\mathrm{X}^{2}\right.$ $=117.9, \mathrm{P}<0.005)$ and perception toward veterinarians' capabilities of educating people $\left(\mathrm{X}^{2}=135.68, \mathrm{P}<0.05\right)$. Almost all $(87.1 \%)$ of illiterate residents responded dealing with only animal health as the role of veterinarians, while the majority $(76.9 \%)$ of respondents that had diploma or above education statues indicated inspecting of food of animal origin and educating people about animal associated risks are also the roles of veterinarians in addition to dealing with animal health. Furthermore, the majority (83.5\%) of respondents that had diploma or above educational statuses believe veterinarians are capable of educating people about animals' related risk, whereas most $(87.1 \%)$ of illiterate respondents believe veterinarians are not capable of educating people about animals' associated risks (Table 6).

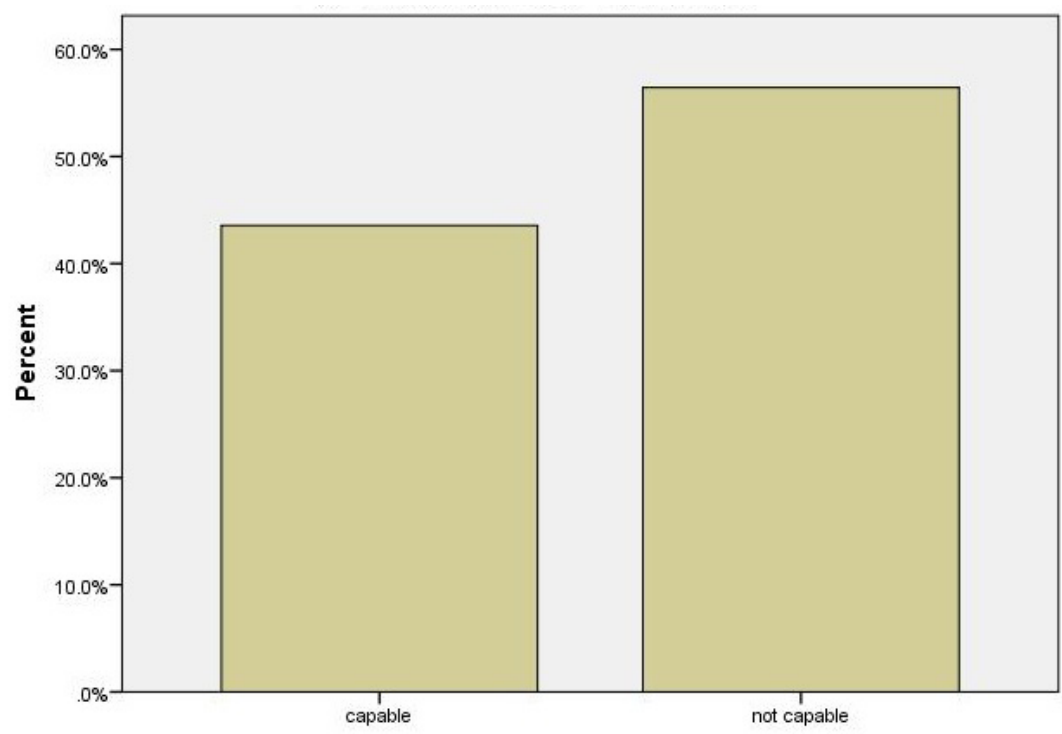

capablities of vets in educating people about animal related risks

Figure 2: Perception of community on veterinarian's capabilities in educating people about animals' related risks 


\begin{tabular}{|c|c|c|c|c|c|c|}
\hline & \multicolumn{3}{|c|}{ Education statuses } & $\mathbf{X}^{2}$ & Df & P \\
\hline & $\begin{array}{c}\text { Diploma or } \\
\text { above }\end{array}$ & $\begin{array}{c}\text { High school } \\
\text { complete }\end{array}$ & Illiterate & & & \\
\hline Variable & $\mathbf{N}(\%)$ & $\mathbf{N}(\%)$ & $\mathbf{N}(\%)$ & & & \\
\hline Veterinarians' role & $28(23.1)$ & $90(86.5)$ & $54(87.1)$ & & & \\
\hline Deal with animal health only & $93(76.9)$ & $14(13.5)$ & $8(12.9)$ & & & \\
\hline $\begin{array}{c}\text { Animal health + inspect food or + } \\
\text { educate people }\end{array}$ & & & & 135.8 & 2 & 0.000 \\
\hline $\begin{array}{c}\text { Capabilities of vets in educating } \\
\text { people }\end{array}$ & $101(83.5)$ & $16(15.4)$ & $8(12.9)$ & & & \\
\hline yes & $20(16.5)$ & $88(84.6)$ & $54(87.1)$ & & & \\
\hline no &
\end{tabular}

Table 6: The relation between some independent variables and education statuses among inhabitants in Arba Minch, Ethiopia 2015

75 physicians, 28 veterinarians and 10 health directors/vice directors were interviewed on their respective questions. Accordingly, the study indicated large proportion of physicians (46.7\%) had never contacted veterinarians to deal with zoonoses. The majority of veterinarians too (35.7\%) had contacted rarely physicians on the same issue. The response of physicians and veterinarians on how often they contact each other to deal with zoonoses was not significantly different P>0.05 (Table 7).

\begin{tabular}{|c|c|c|c|}
\hline Response of Physician & Number (\%) & P value & $\mathbf{X}^{2}$ value \\
\hline Several times & $1(1.3)$ & 0.054 & 16.7 \\
\hline sometimes & $5(6.7)$ & & \\
\hline rarely & $34(45.3)$ & & \\
\hline never & $35(46.7)$ & & \\
\hline total & $75(100)$ & & \\
\hline Response of Veterinarians & & & \\
\hline Several times & $2(7.1)$ & & \\
\hline Some times & $7(25)$ & & \\
\hline rarely & $10(35.7)$ & & \\
\hline never & $9(32.2)$ & & \\
\hline total & $28(100)$ & & \\
\hline
\end{tabular}

Table 7: Response of physicians and veterinarians on how often they contact each other to deal with zoonoses in Arba Minch Ethiopia (2015)

Data obtained from directors/vice directors of health centers revealed higher number (70\%) of directors/vice directors believe that veterinarians are highly capable of educating about zoonoses for the patients. The study also showed the majority of respondents said that, there was no health center/institution/hospital with a department specifically working on zoonoses. Only $40 \%$ of respondents indicated that there was a department specifically working on zoonoses however, all of them had no public health veterinarians in those departments (Table 8).

\begin{tabular}{|c|c|c|}
\hline CONDITIONS/QUESTIONS & $\begin{array}{c}\text { Yes } \\
\text { Number (\%) }\end{array}$ & $\begin{array}{c}\text { No } \\
\text { Number (\%) }\end{array}$ \\
\hline Presence of zoonoses department & $4(40)$ & $6(60)$ \\
\hline Presence of public health veterinarians & $0(0)$ & 4 \\
\hline High consent for veterinarians in rabies education & $7(70)$ & \\
\hline Low consent for veterinarians in rabies education & $2(20)$ & \\
\hline No consent for veterinarians in rabies education & & $1(10)$ \\
\hline
\end{tabular}

Table 8: Response of directors/vice directors' health centers/hospital in Arba Minch Ethiopia (2015)

\section{Discussion}

The findings of this study indicated the majority of inhabitants (42.45\%) that had history of dog bite in Arba Minch, Ethiopia used a treatment by traditional healers, $33.02 \%$ sought medical services and $24.53 \%$ used both traditional and medical services. Analysis of response from all participants (both with and without dog bite history) indicated higher proportion (60.6\%) of participants had moderate preference to traditional healers over public health centers. Ali Abraham et al. reported 58.3\% participants of the study had strong belief on traditional medicine, in Ethiopia [26]. Some consistence studies also reported all victims had attempted 
traditional medicine after exposure to bite, and they finally visited health centers when the traditional methods failed and clinical sings appeared $[23,29]$. Very high number of dog bite victims $(90 \%)$ that received treatment by traditional healers in Bangladesh [30] was also other consistence report. In contrast to this finding, study in Sri Lanka showed almost all participants sought medical care and advises after exposure to dog bite [31]. Other report in Pakistan also demonstrated the majority (69.4\%) of respondents exposed to rabid dog bite were visited health centers to consult doctors [32]. This difference is probably attributed to lack of knowledge about the risks of dog bites and socioeconomic factors of the study area. In open-ended questions of this study, the majority of participants (79.4\%) have testified rabies is the only consequence after exposure to bite, only $20.6 \%$ of participants indicated that, other infections at site of bite, bleeding and Psychological trauma are also risks of bites besides rabies. The idea indicated by large proportion of participants about the risks of bite might have resulted in attempting traditional treatment procedure against rabies only and they might recognize sometimes successful traditional methods in a view of the low frequency of rabies transmission by healthy biting dogs [33]. The statistically significant difference $(\mathrm{P}<0.05)$ between socioeconomic status of the participants and the choices of treatment methods might be due to provision of relatively lower treatment cost by traditional healers. Study on the incidence of human rabies exposure in Gondar, Ethiopia indicated socioeconomic status of the community determines the methods of treatment they prefer [34]. Residents' living area was significantly associated with choices of treatment methods. This could be attributed to the difference in the economic status between urban and rural residents. Study on knowledge, attitude and practices of bite victims in Jimma, Ethiopia [35] also testified similar result. The perception of the respondents to use the methods of treatment after exposure to dog bite varies according to educational status, statistically significant different was observed between educational level and the measure they take to choose treatment methods $\left(\mathrm{X}^{2}=36.3, \mathrm{P}<0.05\right)$. This could be due to more educated people have different sources of information so that they have better knowledge and attitudes towards the risks. Attitude, knowledge and perception score of community about dog bite risks goes high when the educational level advances [36].

Dog keeping practice was not significantly different between urban and rural residents of this study $\left(\mathrm{X}^{2}=3.327, \mathrm{P}>0.05\right)$. However, the study conducted in Addis Ababa, Ethiopia [26] indicated almost all the pet owners keep their pets in secured cages or tied them in the compound. The difference in this comparison might be due to the difference in awareness level about the importance of pets' management in different study area. The study also revealed statistically significant association between residents living area and Vaccination practice of dog against rabies and reason not to vaccinate. None of rural residents had vaccinated their dogs against rabies while very few respondents had vaccinated their dogs in urban residents. The main reasons that the urban residents have not vaccinated their dogs were lack of attention and lack of knowledge, but lack of veterinary services and lack of knowledge were the main reasons in rural residents. Ali Abraham, et al. [26] showed similar report that lack of knowledge about vaccine, lack of services and lack of attention were the reasons not their dogs get vaccinated. Related study [37] also indicated absence of dog vaccination campaign is a reflection of inaccessibility of services. The study also revealed owning the dog was not associated with bite exposure $\left(\mathrm{X}^{2}=0.162, \mathrm{P}>0.05\right)$. However, Study conducted in Australia [38] explains owning the dog closely associates with dog bite exposure. Insignificant association between owning dog and exposure in our study might be due to nearly similar dog keeping practice (let dogs free) in both rural and urban residents' results in equal chance of getting exposed in both owned and non owned families.

Assessment of veterinary public health activities regarding animals' related risk in human between professionals group in the study area suggests communication between physicians and veterinarians is largely poor. According to the survey, veterinarians and physicians response on how often they contact each other to deal with dog bite problem was not significantly different $(\mathrm{P}>0.05)$. Study on the role of physicians and veterinarians in preventing zoonotic diseases showed similar finding [39]. Most reports on dog bite [9-11,26] emphasized success in preventing, controlling and raising awareness about dog bite risks depends on good collaboration between different professions and disciplines, in the public as well as in the private sector, particularly between the fields of human and animal health.

A response from directors/vice directors of health centers/hospital obviously implied most of the public health centers had no department unit that specifically working on zoonoses and lack public health veterinarians even if there is a department, which is consistent with a report in Addis Ababa, Ethiopia [40]. According to some studies [39,40] preventing the spread zoonotic infection in human cannot be achieved without the involvement of veterinarians in public health centers. Veterinarians, because of their sound knowledge on zoonoses have resulted in eradication and control of many zoonotic diseases in the countries where public health veterinarians are the first line professionals in the public health institutions. A good example was a drastically elimination and control of rabies in America by the close of $20^{\text {th }}$ century was as a result of collaborative effort between public health veterinarians, physicians and other sectors [41]. According to some studies [38-42], management and follow up bite human is a key section in the procedure of PEP therapy if the dog is available. When dog is considered healthy, these follow up section is essential to discontinue vaccine series since is very expensive for the community with low socio economic status [42]. Interview with directors/ vice directors of health centers/hospital was also a good indicator of high consent for veterinarians in zoonoses education to the communities. For example in Belgaum City, Nayak et al. [43] had also indicated the majority of animal and human exposures to rabies virus can be prevented by public education which is a responsibility of veterinarians too besides physicians. 
This study also indicates dealing with animals' health only which was mentioned by the majority of respondents as the role of veterinarians clearly implies that there is inadequate awareness of the community about veterinarians' role in their working environment which was also mentioned by Bousfield and Brown [44]. The statistically significant difference $(\mathrm{P}<0.05)$ between knowledge of veterinarians' role and educational statuses could be attributed to more educated people access the information easily and school is also other source where they acquire the information. The veterinarians' role to educate their clients at their working circumstances which is a key element to reduce public health hazards associated with animals and their products has been mentioned by many scholars [40,45]. But this study demonstrated the majority (56.4\%) of respondents believe veterinarians are not capable of educating clients about animals' associated risks however, statistically significant difference $(\mathrm{P}<0.05)$ was observed between this perception and educational statuses.

\section{Conclusion}

The results of this study indicate the majority of Arba Minch inhabitants receive treatment by traditional healers after exposure to dog bite. The study also demonstrated absence of strong department and professional group in public health centers that work on zoonoses and lack of communications between veterinarians and physicians in the area which are key elements of veterinary public health activities. And these have restricted veterinarians' contribution to public health in their work place and resulted in inadequate awareness of the community about veterinarians' role. Out of 287 inhabitants, 106 (36.9\%) of victim families in the past two years was a reflection of high dog bite incidence of the area, therefore we would like to recommend that; study on incidence of dog bite and prevalence of rabies in human and dog in the area should be encouraged, strong participatory education about the risk of dog bites and rabies should be given to the residents of the area. And it is also mandatory to set veterinary public health structure and ensure collaboration of professionals within that structure to control and prevent zoonoses and other animal related hazards.

\section{Acknowledgements}

I would like to thank Arba Minch inhabitants who participated in the study. Special thanks to veterinarians, physicians and directors of health centers of the area that played their part in the study. I would also like to extend my gratitude to agricultural office, department of animal health and quarantine services of southern region, Merab Abaya district of Ethiopia for materials and logistic service support.

\section{Supplementary Information}

\section{References}

1. Sacks JJ, Sinclair L, Gilchrist J, Golab GC, Lockwood R (2000) Breeds of dogs involved in fatal human attacks in the United States between 1979 and 1998 . J Am Vet Med Assoc 217: 836-40.

2. Fekadu M (1982) Rabies in Ethiopia. Am J Epidemiol 115: 266-73.

3. Deressa A, Ali A, Bayene M, Selassie BN, Yimer E, et al. (2010) The status of rabies in Ethiopia: A retrospective record review. Ethiop J Health Dev 24: 128-9.

4. Jemberu WT, Molla W, Almaw G, Alemu S (2013) Incidence of Rabies in Humans and Domestic Animals and People's Awareness in North Gondar Zone, Ethiopia. PLoS Negl Trop Dis 7: e2216.

5. Heymann DL (2008) Rabies. In: Control of Communicable Diseases Manual (19 $9^{\text {th }}$ Edn) American Public Health Association, Washington.

6. Abuabara A (2006) A review of facial injuries due to dog bites. Med Oral Patol Oral Cir Bucal. 11: E348-50.

7. Kreisfeld R, Harrison J (2005) Dog related injuries. Australian Institute of Health and Welfare (AIHW) National Injury Surveillance Unit at Flinders University, Bedford Park, South Australia.

8. Tefera G, Yimer E, Geyid A (2002) Endemic existence of rabies in Ethiopia. Ethiop Med J 40: 163-70.

9. Charles ER (2006) New Challenges to Rabies Prevention and Control in Veterinary Medicine and Public Health. Leadership Public Health 7: 20-2.

10. Gershman KA, Sacks JJ, Wright JC (1994) which dogs bite? A case control study of risk factors. Pediatrics 93: 913-17.

11. Overall KL, Love M (2001) Dog bites to humans-demography, epidemiology, injury, and risk. J Am Vet Med Assoc 218: 1923-34.

12. Abebe AM, Hurisa B, Urga K (2016) Current Situation of Rabies Prevention and Control in Developing Countries: Ethiopia Perspective. J Anc Dis Prev Rem 4: $1-6$.

13. Mengistu F, Hussen K, Ali A, Getahun G, Sifer D (2011) Dog bite as a public health concern in Addis Ababa. Ethiop J Health Dev 25: 59-60.

14. Center for Disease control and prevention (CDC) (2011) Compendium of Animal Rabies Prevention and Control, National Association of State Public Health Veterinarians, Inc. MMWR 60: 3-5.

15. Dean DJ, Baer GM, Thompson WR (1963) Studies on the local treatment of rabies infected wounds. Bull World Health Organ 28: 477-86.

16. World Health Organization (WHO) (2010) Rabies vaccines WHO position paper. Weekly Epidemiological Record 32: 309-20.

17. Tepsumethanon V, Lumlertdacha B, Mitmoonpitak C, Sitprija V, et al. (2004) Survival of naturally infected rabid dogs and cats. Clin Infect Dis 39: 278-80.

18. CDC (2008) Human Rabies Prevention in United States. MMWR 57: 1-28.

19. Frana TS, Clough NE, Gatewood DM, Rupprecht CE (2008) Post marketing surveillance of rabies vaccines for dogs to evaluate safety and efficacy. J Am Vet Med Assoc 232: 1000-2.

20. WHO (2007) WHO recommendations on rabies post-exposure treatment and the correct technique of intradermal immunization against rabies, Geneva, Switzerland.

21. Ontario Public Health Standards (OPHS) (2013) Rabies Prevention and Control Protocol. Operational roles and responsibilities on rabies, USA. 
22. Coleman PG, Fevre EM, Cleaveland S (2004) Estimating the public health impact of rabies. Emerg Infect Dis 10: 140-2.

23. Yin W, Dong J, Tu C, Edwards J, Guo F, et al. (2013) Challenges and needs for China to eliminate rabies. Infect Dis Poverty 2: 23.

24. Deribe K, Meribo K, Gebre T, Hailu A, Ali A, et al. (2012) The burden of neglected tropical diseases in Ethiopia, and opportunities for integrated control and elimination. Parasit Vectors 5: 240.

25. Ali A, Mengistu F, Hussen K, Getahun G, Deressa A, et al. (2010) Overview of Rabies in and around Addis Ababa, in Animals Examined in EHNRI Zoonoses Laboratory Between, 2003 and 2009. Ethiop Vet J 14: 91-101.

26. Ali A, Ahmed EY, Sifer D (2013) A Study on Knowledge, Attitude and Practice of rabies among residents in Addis Ababa, Ethiopia. Ethiop Vet J 17: $19-35$.

27. CSAE (2007) National statistics of Ethiopia. The Population and Housing Census of Ethiopia utilities, Ethiopia.

28. Levy PS, Lemeshow S (1999) Sampling of Populations: Methods and Applications, ( ${ }^{\text {rd }}$ Edn) John Wiley, New York.

29. Yimer E, Mesfin A, Beyene M, Bekele A, Taye G, et al. (2012) Study on knowledge, attitude and dog ownership patterns related to rabies prevention and control in Addis Ababa, Ethiopia. Ethiop Vet J 16: 27-39.

30. Rumana R, Sayeed AA, Basher A, Islam Z, Rahman MR, et al. (2013) Perceptions and treatment seeking behavior for dog bites in rural Bangladesh. Southeast Asian J Trop Med Public Health 44: 244-8.

31. Matibag GC, Ohbayashi Y, Kanda K, Yamashina H, Kumara WR, et al. (2009) A pilot study on the usefulness of information and education campaign materials in enhancing the knowledge, attitude and practice on rabies in rural Sri Lanka. J Infect Dev Ctries 3: 55-64.

32. Salahuddin N, Jamali S, Ibraheem K, Sardar S (2011) Awareness about Rabies Post Exposure Prophylaxis in Pakistan among Patients and Health Care Workers: Results from an Asian Rabies Expert Bureau Study. J Coll Physicians Surg Pak 21: 491-4.

33. Wandeler AI, Matter HC, Kappeler A, Budde A (1993) The ecology of dog and canine rabies: a selective review. Rev Sci Tech 12 : 51-71.

34. Yibrah M, Damtie D (2015) Incidence of human rabies exposure and associated factors at the Gondar Health Center, Ethiopia: a three-year retrospective study. Infect Dis Poverty 4: 3 .

35. Kabeta T, Deresa B, Tigre W, Ward MP, Mor SM (2015) Knowledge, Attitudes and Practices of Animal Bite Victims Attending an Anti-rabies Health Center in Jimma Town, Ethiopia. Plos Negl Trop Dis 9: e0003867.

36. Serebe SG, Tadesse KA, Yizengaw HA, Tamrat SM (2014) Study on community knowledge, attitude and practice of rabies in and nearby Gondar town, North, West, Ethiopia. J Public Health Epidemiol 6: 429-35.

37. Brooks R (1990) Survey of the dog population of Zimbabwe and its level of rabies vaccination. Vet Rec 127: 592-6.

38. Dendle C, Looke D (2009) Management of mammalian bites. Aust Fam Physician 38: 868-74.

39. Sara G, Olsen CW (1999) Preventing Zoonotic Diseases in immunocompromised Persons: the role of physicians and veterinarians. Emerg Infect Dis 5: $159-63$. 40. Girma S, Zewde G, Tafess K, Jibat T (2012) Assessment of awareness on food borne zoonosis and its relation with Veterinary Public Health Services in and around Addis Ababa, Ethiopia. Ethiop Vet J 16: 15-22.

41. Vitasek J (2004) A review of rabies elimination in Europe. Vet Med Czech 49: 171-85.

42. Baydack R, Rusk R (2012) Rabies: Protocol for Management of Human Rabies and Management of Animal Exposures to Prevent Human Rabies.

43. Nayak RK, Walvekar PR, Mallapur MD (2013) Knowledge, Attitudes and Practices regarding Rabies among general practitioners of Belgaum City. Al Ameen J Med Sci 6: 237-42.

44. Bousfield B, Brown R (2011) The veterinarian's role in food safety. Vet Bull Agri Fish Conserve Dept 1: 6-10.

45. de Moissac JE (2009) Veterinarians in public health: Challenges and Opportunities. Can Vet J 50: 897-8.

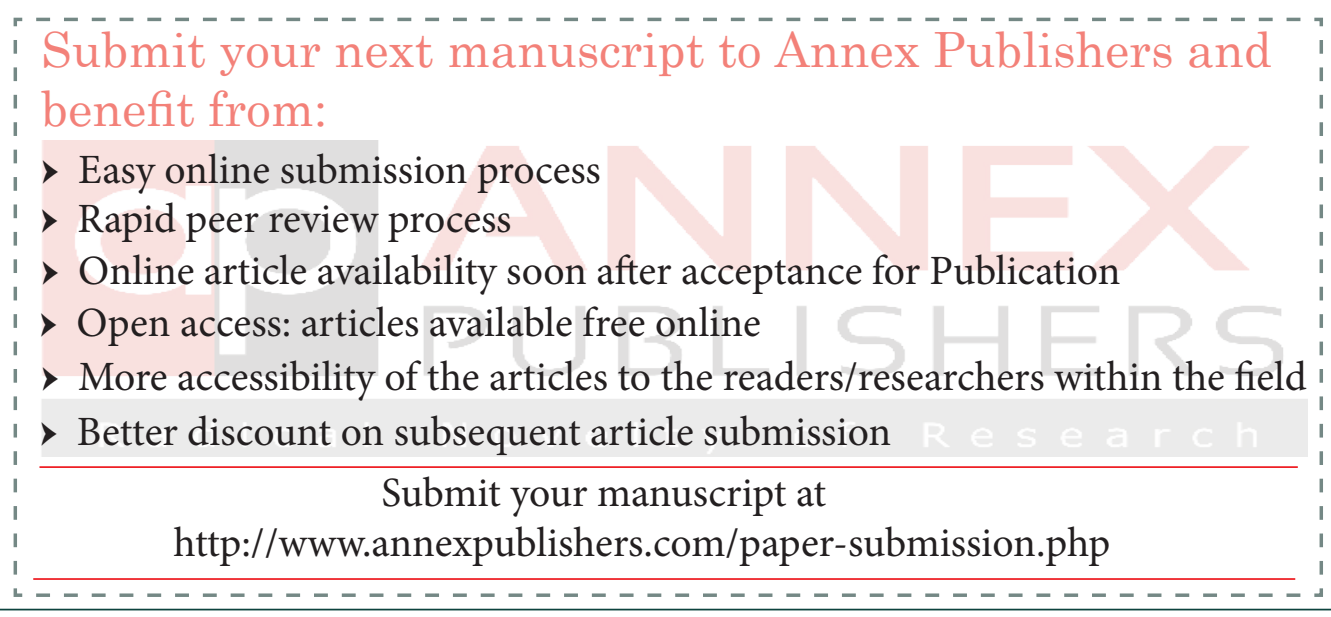

